interesting note are really due to the proper motion of the principal component of this triple star.

LALANDE 23726 (CORVUS). - With reference to the query as to actual brightness of this star, which has been noted as high as a fifth magnitude by Heis 'NATURE, vol. xii. p. 27), Mr. J.E. Gore writes from Umballa, under date June 8:-"I last night examined its place and found the star in question to be barely visible in an opera glass or about mag. 8." It is evidently variable to a considerable extent, and should be closely watched. Mr. Gore adds that " L. $23675-76$ rated $7,7 \frac{1}{2}$ by Lalande, is now about $6 \mathrm{~m}$., and brighter than the stars L. $23463(6 \mathrm{~m}$.) and $23446(6 \mathrm{~m}$.), a little to the west ; "the observations in the Histoire Céleste, however, do not belong to the same object, but to the two components of a double-star, which is $\Sigma I 669$, and in the Dorpat scale were both estimated 6.5 in Mensure Micr., and 6.0 in Positiones Media; their distance about $5 \frac{1}{2}$ ". Bessel also observed both components, judging them of equal brightness and of the seventh magnitude in his scale. The appearance of the object to the naked eye as a bright sixth, remarked by Mr. Gore, is thus accounted for.

Horizontal ReFraction on Venus.-In May I849' near the inferior conjunction of Venus with the sun, Clausen having remarked that the crescent extended beyond a semicircle, Mädler observed it with the Dorpat telescope, with the view of approximating to the amount of horizontal refraction in the planet's atmosphere. Measures, properly so called, he found were haxdiy feasible, owing to the extreme faintness of the cusps and proximity of the planet to the sun, but estimations with a position-wire in the field of view were made on six days at distances varying from $3^{\circ} 26^{\prime}$ to $7^{\circ} 37^{\prime}$; lithe mean gave for the horizontal refraction, $43^{\prime} \%$. In 1866 Prof. C. S. Lyman, by similar observations, obtained $45^{\prime} \cdot 3$; he remarked: "The planet was then (for the first time, as it appears) seen as a very delicate luminous ring. The cusps of the crescent, as the planet approached the sun, had extended beyond a semicircle, until they at length coalesced and formed a perfect ring of light." Last December Prof. Lyman repeated these observations, making use of a five-feet Clarke telescope of $4: 2$ inches aperture, and by measures of the extent of the crescent on four days, deduces for the horizontal refraction of the atmosphere of Venus, $44^{\prime} \cdot 5$, a value which is also the mean of the three sets of observations. (American Fournal of. Science and Arts, January I875). At the next inferior conjunction of Venus, she will have the following angular distances from the sun's centre, at Greenwich noon :-

$$
\begin{array}{crrrr|rrrrrr}
1876, \text { July } & \text { II } & \ldots & 6^{\circ} & 28^{\prime} & \text { July } & 14 & \ldots & \ldots & 5^{\circ} & 8^{\prime} \\
,, & 12 & \ldots & 5 & 35 & y & 15 & \ldots & \ldots & 5 & 33 \\
, y & 13 & \ldots & 5 & 5 & , & 16 & \ldots & \ldots & 6 & 23
\end{array}
$$

The formula used for finding the horizontal refraction may be thus written, putting $C$ for the observed extent of the crescent, $d$ for the angular distance of Venus from the sun at the time of observation, $s$ for the sun's semidiameter, which we may express in minutes of arc, and $r$ for the planet's radius-vector :-

$$
\text { Hor. Refr. }=\frac{I}{2}\left\{\operatorname{Arcsin} d \sin \frac{1}{3}\left(C-I 80^{\circ}\right)-\frac{s}{r}\right\}
$$

THE SUn's PARALlaX,--We have received Prof. Galle's Bestimmung der Sonnen-Parallaxe aus correspondirenden Beobachtungen des Planeten Flora (Breslau, $\mathrm{I} 875$ ), which contains the full details of his reduction of the observations taken in both hemispheres near the opposition of the planet in 1873, when it approached the earth within about 0.87 of our mean distance from the sun. The final result for the parallax $8^{\prime \prime} .873$, as already stated in this column, corresponds to 23,247 equatorial semi-diameters of the earth, or, according to Galle, $19,979,000$ geographical miles of $I 5$ to the degree of the equator.

\section{SCIENCE IN SIAM.}

WHEN the invitation of the King of Siant to observe the late total eclipse of the sun reached the Royal Society, it was hailed with delight by those who took an interest in the expedition. A few Europeans professing to know something about the country wrote letters to newspapers discouraging astronomers from accepting the invitation. Happily no notice was taken of these anonymous letters, and the result was that the members of the expedition were surprised, not only by the good reception they met with everywhere in Siam, but also by the great interest the Siamese themselves took in the eclipse and in science generally. The late king was well known for his love of astronomy, but many might suppose that this was a solitary case, and that with the death of the king science would be left unprotected in the country. A short account of our experience will show that the interest the Siamese take in science is rather on the increase than on the decrease.

On our way to the observatory, which was erected at Bangtelue, near Chulie Point, we had to stop twenty-four hours in Bangkok until the steamer which was to take us was ready. It happened that the evening of that day the "Young Siamese Society" met in the house we were staying at, and $\mathrm{I}$ was asked by the members to give a lecture on spectrum analysis and its application during solar eclipses. Mr. Alabaster, aided by the King's private secretary and Prince Dewan, acted as interpreter. The Siamese listened with the greatest interest, and by the questions they asked after the lecture was over showed that they fairly understood the subject. There exists a Siamese translation of a book on chemistry, and they had read up the subject in that book. H.R.H. Chowfa Maba Mala, uncle of the King, is the chief astronomer of the Siamese at the present time. He showed me the way in which he had determined the time and duration of the eclipse at Bangkok. Taking the sun and moon's apparent diameter from the Nautical Almanac, he determined by means of the projection of their paths and their apparent velocity the time of the different contacts. The drawing was neatly executed and, I am told, the time thus determined came very near the truth.

On the day of the eclipse several telescopes, one of which had been lent to the King by Dr. Janssen, were set up on the lawn in the front of the palace. The local time was determined by Mr. Alabaster and Capt. Bush, in order to find the exact time of the different contacts. As totality approached, the King made a speech to the members of the Royal Family, who were all assembled, telling them why solar eclipses were observed, and why large sums of money were spent for that purpose. During totality, his Majesty observed the corona and the protuberances through a telescope, carefully noting down what he saw and making a sketch of the protuberances. He had ordered one of the princes to take photographs of the corona. Two photographs were thus secured, which by no means are inferior to those taken at the Observatory of Bangtelue. The original negatives of these photographs have been sent to England as a present from the King to the Royal Society.

At our camp the Siamese also showed a great interest in the eclipse. The eagerness with which the ex-Regent looked through his telescope contrasted in a characteristic way with the quiet indifference with which his European secretary went to sleep during totality.

The King of Siam informed us that he did not profess to be an astronomer, and I was therefore rather surprised to hear afterwards that on his journey to Calcutta he had taken regular sights with the sextant, and calculated himself the position of the steamer.

But the taste of the Siamese for science is not merely confined to astronomy. Wangna, the second king, is a mineralogist. The country in which he lives gives him ample opportunity to work at his favourite subject. $\mathrm{He}$ 
has a large mineralogical collection and a nice chemical laboratory, in which he makes his analyses.

Let us now turn from what the Siamese have done for science to what they are going to do.

The King has instructed Dr. Gowan to erect an observatory in which regular barometric and thermometric measurements are to be made. The rainfall and the tides will also form a subject of measurements. Other instruments will be added in time. As the Siamese have a great fancy for photography, we shall perhaps soon see regular photographs of the sun taken in Bangkok. Various spectroscopes and telescopes are at the present moment on their way out from England. It is also intended to build a chemical laboratory in the palace. The King's bodyguard are being instructed by $\mathrm{Mr}$. Alabaster in taking surveys. At the moment I write this, they are out on a surveying expedition.

All this shows that the inhabitants of Siam have a great fancy for science, if it does not show more. Strong liking for a subject is generally accompanied with, if not caused by, the ability to deal with it and to overcome its difficulties. Let us hope that some of the Siamese will take up their favourite subject, not as amateurs merely, but with all the seriousness of a profession. Many of them visit Europe for several years. If some of these were to go through a course of science, the knowledge thus gained, added to their natural intelligence and love of science, would soon make them good observers and able experimenters.

In the meantime it will be interesting to watch the growth and development of a country in which science is the recognised and favourite study. English men of science cannot refuse their sympathy to a king who, under great difficulties, does his best to improve his country, and who readily accords to science the position which they are striving to obtain for it in their own land.

\section{ARTFUR SCHUSTER}

\section{THE RESTING-SPORES OF THE POTATO FUNGUS}

TiOR some reason unknown to me (but probably owing to meteorological conditions pertaining to this season or the last) the potato fungus began its ravages this summer a month or six weeks earlier than usual. It not only appeared out of season, but it came in a different form from anything within the memory of the younger botanists of the present generation. It is considered probable that the present condition of the disease is similar with that long ago known as "the curl," a pest known a considerable time before Peronospertr ingestans, Mont., was described as European.

At the begiming of June I had potato-leaves sent to me for examination from the office of the Foum nal of Horticulture; these leaves were badly diseased, spotted and foctid, and from certain of the stomata a few threads of the Peronospora were emerging; this fact, from the unusually early appearance of the fungus, I made a special note of.

On June I6 Mr. Berkeley brought leaves sent to him for examination by Mr. Andrew Murray, (which were spotted in an exactly similar manner with mine), to the mecting of the Royal Horticulturat Society. At the same time Mr. Berkeley exhibited a sketch of two rather large nodulose (or reticulated) bodies found by him within these leaves, as a possible species of Protonyces, but since then known to be the resting-spores of Peronospora infestans, Mont., here illustrated.

The presence of these warted bodies in the leaves, as seen by Mr. Berkeley, led me to make a searching examination of the Chiswick plants then greatly suffering from the pest, and $I$ at once found similar bodies very sparingly diffused amongst the tissues of the leaves, with a few branches of Peroriospora and threads of mycelium, and two semitransparent bodies of different sizes which were new to me. On attempting to disengage these presumed speci- mens of Protonyces from the black, hard, and corroded spots on the leaves by maceration in water, I found the continued moisture greatly excited the growth of the mycelium. After the lapse of a weel. the threads bore (amongst the intercellular spaces of the leaves) the semitransparent bodies of two sizes which I had before seen and measured, and which I now refer without doubt to the oogonium and antheridium of the potato fungus. It is very uncommon to find a fungus bearing sexual and asexual fruit at the same period of growth, and in this instance the old asexual fruit was very sparingly produced. I, however, afterwards found the fungus with both forms of fruit and with ripe free resting-spores, inside the cavities of the putrid stems, and I found the ripe resting-spores and the sexual organs sometimes in conjugation within the tissues of the potato tubers when the substance was reduced by decomposition to the softness and semi-transparency of butter.

By keeping the potato-plants closely under observation from that time to this, a period of from six to seven wecks, I have seen and figured these bodies in every stage of growth, and have been able to preserve some of the best material for future careful mounting. Those who maj" care to know in detail how, from the slightest clue at first, the subject was worked out to its present aspect may refer to the Gardener's Chronicle for July 10, 17, and 24 . last, and to this week's Fonmal of Horticulture.
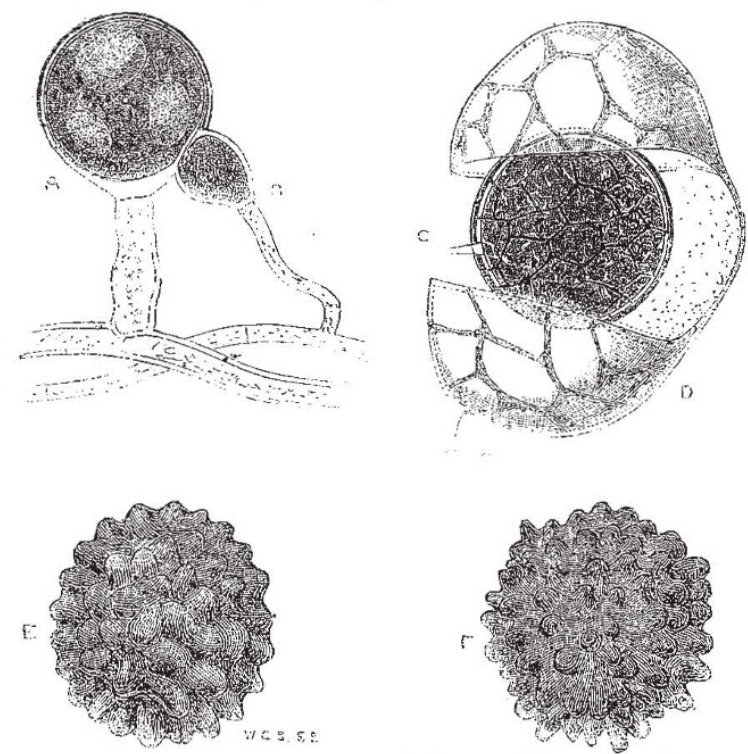

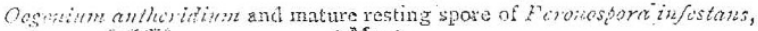
asto

i. Mont.

The antheridia, oogonia, and oospores (or resting-spores) in Peronosyora infesions, Mont. are very similar, with the same bodies in other species of Peronosporc, in fact when they are drawn to scale and placed side by side there is very little difference to be detected. The accompanying illustration shows the oogonium $(\Lambda)$ and antheridium (B) in contact as taken from the tissues of the leaf, At $C$ is shown a semi-mature resting-spore with its fecundating tube attached and its coat of cellulose accidentaily pushed aside by maceration in water, as taken from a putrid potato-stem. At $\mathrm{E}$ is illustrated the perfectly mature resting-spore, free from its coat of cellulose taken from a tuber in the last stage of decomposition. At $\mathrm{F}$ is shown the resting-spore of Peronospora arenaria, Berk, drawn to exactly the same scale to show similarity in size and conformation. The figures in the cut are uniformly enlarged seven hundred diameters, and the mature oospore or resting-spore measures on the average 00142 inch in in length, and oor is inch in breadth.

WORTIINGTON G, SMITH 